\title{
Nursery Rhymes and the Social-Construction of Gender Roles
}

\author{
Qurratulain Nasiruddin
}

\author{
The University College London, \\ United Kingdom
}

\section{Doi:10.5901/jesr.2013.v3n4p77}

\begin{abstract}
Language, besides a mode of communication, is a powerful medium of change in a society. Through language, ideas and perceptions are communicated to people. In specific, these ideas and perceptions get strength if the language is being taught in formal educational systems such as schools. Considering the pre-operational cognitive abilities of nursery school children aged between three to seven years, this paper argues that nursery rhymes are instrumental in making and changing gender perceptions in Pakistani society. The paper evaluates certain nursery rhymes taught in both manners, formally in schools and informally at home. The rhymes are mainly in Urdu language but translation has been provided in order to make argument more comprehensible. The study has potential to be carried forward from the lens of gender studies and linguistics. However, this paper limits discussion in two main dimensions: nursery rhymes as an instrument of social change and gender roles in Pakistani society.
\end{abstract}

Key words: Gender, nursery rhymes, society, education, children

\section{Introduction}

Language, along with helping in communication, tends to build a sense of solidarity amongst people of a same society. Particularly, in these solidarities, language functions as a powerful carrier of thoughts and ideas; hence shaping the perceptions of a society about certain social roles. Such exotic and diverse functions of language have caught the attention of sociolinguistics and anthropologists who consider language as a powerful instrument for shaping social behaviors of people. One of such anthropologists, Elinor Ochs (1988) studied the role of language in socialization among the children of Samoan village. She informs that language plays a vital role in the transmission of knowledge and transformation of social behaviors of children. Based on her study, this paper argues that nursery rhymes are powerful tools for the transmission of knowledge to children.

Being a part of the Pakistani society where I learnt nursery rhymes as part of my schooling and home education, I am certain in saying that nursery rhymes have an influence on the thinking and perceptions of people in Pakistan. This paper is interested in examining those nursery rhymes. These rhymes are still taught to Pakistani children aged between four to six years of age. Basically, these rhymes are available in the national language of Pakistan that is Urdu (See the Appendix). Efforts have been made to provide translations; however it was not possible for every rhyme. Within the scope of the paper, the rhymes are studied from a sociolinguistic perspective. However, the same rhymes have potential of being studied from a linguistic aspect.

There are two basic reasons for examining the rhymes. Firstly, rhyme is a kind of narrative (a genre in linguistics) that constitutes a crucial resource for socializing emotions, attitudes and 
identities where self and society interface each other (Ochs and Capps, 1996). From a linguistics point of view, rhymes are a powerful way of transmitting knowledge in the society.

Secondly, nursery rhymes are often taught to and learnt by the children of ages 2 - 7years, both girls and boys. This age group falls in the category of 'pre-operational cognitive abilities' as identified by Piaget (1952). In accord to Piaget's categorization, the children with pre-operational capabilities cannot understand social behaviors on the grounds of logics and rationality. Consequently, children acquire knowledge from their surroundings as it is. Henceforth, the fragility of consciousness during this age period demands extra vigilance and critically about the knowledge transmitted through nursery rhymes.

\section{Language and society}

Ochs (1988) analyses the function of language in the construction of social phenomenon. Her study suggests that children acquire the tacit knowledge of their society through language.

Perhaps, it is not just the words that people exchange while interacting with each other. Indeed, people tend to convey their thoughts, feelings, ideas and opinions by means of those words. The way of interaction between people may also reflect the social roles each individual play in the society. For that reason, the acquisition of the knowledge about a language and the sociocultural knowledge are interdependent (Ochs, 1988). The interdependency of language and the culture of the society makes the process more interactive.

Language conceals various symbols and metaphors (Vygotsky, 1962). As mentioned earlier, language just not only communicate words. Rather the words, in the form of symbols, unfold social messages either explicitly or implicitly. The interaction amongst people tends to get strength if the message communicated through language harmonizes the social behaviors of people. These interactions themselves are symbolic, and people as active participants interpret those symbols (Schieffelin \& Ochs, 1986). For example, a Muslim child learns to greet others by saying salam which means 'be peace upon you'. The child may wonder over the use of this word while greeting one's enemy. Nonetheless, the message communicated through the word salam suggests that a person must pray for peace and safety of everyone including enemies and rebels. Conversely, the social messages often remain unnoticed by people especially with the widespread use of a language.

In this discussion, the role of children is very important. Piaget (1952) said that children are constructor of their own development. In accord with his views, children possess the tendency of giving new interpretations to the symbols used in their language. Nevertheless, this tendency may deteriorate if children are misinformed of the interpretations of these symbols. For instance, Mushtaq and Rasul (2012) found that the nursery rhymes taught in Pakistan portrays gender discriminated social roles. In this case, there is a high tendency that children actualize social roles according to gender differences. This learning may reflect through their social behaviors and interactions. Therefore, it appears crucial to examine the knowledge conveyed through rhymes. As Doležalová (2007: 21) states that:

"Fashions come and go, but children still repeat the favorite and famous old nursery rhymes. When parents recite old nursery rhymes to their children, they provide them the first important step to their children".

These words indicate that knowledge attained in the form of nursery rhymes lasts longer. It means that the knowledge acquired through rhymes may pose an impact throughout the life of a person.

As not all children may get an opportunity to validate their learning, by means of the formal education system, and they tend to carry the same throughout their life believing it to be correct knowledge. For instance, Wallowitz (2004) accuses nursery rhymes and fairy tales for introducing biased perceptions about gender during early childhood. Thus, not all people are fortunate enough 
to reflect back their childhood knowledge and identify the problems. Similarly, Mushtaq and Rasul (2012) found the misinterpretation of gender roles in Pakistani nursery rhymes; and this paper shares the same interest.

Gender, in this paper, is seen as a socially-constructed phenomenon. A conventional perception of gender, being based on physiology, provides a valid justification for female suppression and gender hierarchy (Moore, 1994). However, this paper follows the statement by Simon de Behaviour that "one is not born, but rather becomes a woman" (Connell, 2002: 4). Accordingly, both men and women undergo the social process of 'becoming' a man or a woman in their course of life rather being a man or a woman biologically.

In the process of 'becoming a man or women' the role of language cannot be ignored (Ochs, 1988). From a linguistic point of view, the discourse of gender can be understood on the basis of the performative category of language (Butler, 1990). Gender is performed as a role by our bodies. The roles are assigned without our consent. Language works as a structure, which dictates our behavior and demands us to act according to the pre-written script. The symbols used in language reinforces certain attitudes which not only work literally but also construct meanings by its frequent usage over a period of time. It means that over-emphasizing of a gender role by means of rhyme has a potential of embedding those meanings, whether correct or incorrect. Therefore, on one hand, the responsibility lies on educationalists, parents, curriculum-developer, teachers and everyone responsible for nurturing of children to scrutinize the knowledge a child receives. On the other hand, it's the task of anthropologists, linguistics and sociologists to help them fulfil their responsibilities by examining the symbolic interaction of language and society.

\section{Nursery Rhymes and the Construction of Gender}

In light of the above discussion, this part of the paper examines several nursery rhymes taken from the books taught in montessories and pre-primary schools in Pakistan (Mumtaz, not dated). These rhymes are not only taught in schools and formal educational systems. They are sung and hummed by parents and elders while playing and informal interactions. An examination of these rhymes suggests that children get a biased knowledge about gender roles through rhymes which sometimes reflects from the social behaviors of the Pakistani society; but not truly captures the transitions in these behaviours.

There are two famous rhymes taught in pre-primary schools, these are: 'piyari baji' (See Appendix 1) and 'machali ka bacha' (See Appendix 2). Both of these rhymes respectfully present the role of women. In these rhymes, women are appreciated for their care, compassion and responsibility towards family members. In the first rhyme, a boy praises his older sister for her care and compassion. Similarly, the second rhyme portrays a mother as someone who brings joy and happiness in family by cooking and feeding delicious foods. However, the later rhyme also depicts a conventional attitude of Pakistani society towards women. The child, in the second rhyme, went for fishing with his brother and father while mother was doing house chores. When they returned, his mother cooked and served fish that made everyone happy. It seems to be a typical image of a mother who, as a housewife, manages household activities while men (brother and father) go out. Simultaneously, the mother is shown as the reason of pleasure and satisfaction.

To a certain extent, the roles of women explained in these rhymes do not portray contemporary Pakistani society. Though Pakistan is still perceived as a patriarchal society but the perceptions about women has been changed drastically in some parts of Pakistan. Jehan (2000) informs that around $42 \%$ of the economy of Pakistan is contributed by women (both rural and urban) by working fields, offices, industries or teaching. It means that women in Pakistan are equally active as men but lack of unrevised publications about the status of women in Pakistan does not help people changing their perceptions about Pakistani society. Unfortunately, in another poem 'jab hum chottey the' (See Appendix 3) mother is presented with an ill-image. In the poem, children are recalling their childhood. While recalling they complaint that whenever they cried, their 
mother used to beat them; whereas father used to bring sweets. Moreover, the children cheered over the moments when their mother got envious of seeing those eating sweets.

Perhaps, this particular rhyme brings about several contentious aspects of gender roles in a family. At the outset, mothers are shown insensitive towards the need of children and, so she beats even when the child cries. From a different perspective, it appears as if mother is concerned about the discipline of the children while father is spoiling the children by bringing those sweets. Simultaneously, father appears to be disrespectful towards the decision of the mother. He brought sweets even when the mother was not in favour. It shows a sort of disagreement in the attitude of mother and father towards nurturing of their children which is also acknowledged by children. As the reason to cry is not well-stated, it seems difficult to make a guess whether mother was beating children for the sake of good or not. In any case, child beating (regardless of any reason) is a well contested debate (Korbin, 1981); therefore mother appears to be guilty of beating children. Following, father is shown as the only person responsible for bringing joy and happiness to the children. These lines provoke feminist voices against neglecting women's contribution and outdoor roles in a family.

Other rhymes illustrate women in the role of wife and sister. The poem cham cham (See Appendix 4) is a very well-known rhyme chanted by children while playing a game called cham cham. The last few lines of this poem portrays a scenario where kids are excited in finding a bride for their brother. In the later part a girl who married their brother is projected as ugly and fastidious that upsets the brother. On similar lines another rhyme is tot batot (See Appendix 5) that narrates the story of tot batot (a character) whose life got ruined after getting married. It is commonly believed in that society that marriage significantly changes the life of an individual but, it is biased to say if only man's life get change. As the character in this poem is male, so this poem conveys an idea that a woman spoils the life of her husband. Indeed, the last paragraph depicts a malicious image where his wife ran away with all the money and turned marriage as a sarcasm.

These rhymes present some conventional thoughts and perceptions about brides and marriages in Pakistani society that are transmitted to a new generation, unfortunately, through education. Conventionally, many families in Pakistan expect a bride to be beautiful and not arguing (Faridi, 2009). With this image, several parents tend to not let their son marry a girl who is manish, unattractive or highly educated (as it is believed that highly educated girls argue more than uneducated girls). It is also another fact that marriage is a subject of sarcasm and irony among youth of Pakistan. Young boys appear to make fun of the one who gets married as it is believed that marriage overpowers one's freedom. Nevertheless, the trends and perceptions are gradually changing in Pakistani societies through education and media (Faridi, 2009). Currently, many families in Pakistan allow their children (daughters and sons) to marry by their wish; however there are still some places, both urban and rural areas, where children undergo forced marriages (Faridi, 2009). Thus, attitudes and perceptions of Pakistani societies are changing but not evenly.

The same character in the latter rhyme is a subject of irony in the other poem known as tot batot ki appa (See Appendix 6). Unlike the previous rhyme, tot batot is humiliated because of his sister. His elder sister is presented as a delicate yet quarrelsome character that often fights and weeps for no reason. Interestingly, there are two similarities in both the poems. Firstly, both poems show that tot batot, who is a man, is a subject of humiliation and sarcasm because of feminine characters. Secondly, women are shown more powerful through their action (as the wife ran away) or status (elder sister) but not sensible enough as the society expected her to be.

It might be a reason that misbehavior, emotional dependency and immaturity of women presented through these rhymes are due to illiteracy of the women that is reflected in female characters. Jahangir (1988) claims that women in Pakistan are not privileged to enjoy freedom of education and other social rights as men do. Similarly, the report of Human Development in South Asia (2007) shows that the literacy rate is $64 \%$ for male and $36 \%$ for female in Pakistan. On the basis of these reports, one may understand that not all women in Pakistan are exposed to modern thoughts and social norms. It might be a reason that men find their spouses ill-mannered and 
backward. Personally, I disapprove the pseudo-representation of women in such rhymes for at least two reasons. Firstly, such a representation is an overgeneralization of the mentioned characteristics for all women in the society. Secondly, these rhymes do not take into account the factors responsible for the social behaviours of women.

Referring Ochs \& Scheffelien (1979: 64), nursery rhymes as 'communicative acts' hold great importance in the transmission of knowledge to children and in the development of their attitudes and perceptions about the society. The mentioned rhymes have been taught to different generations of children in Pakistan. The perceptions of Pakistani society about gender, including women, mother, father, sisters, brides and marriages, have been changed (Faridi, 2009). Unfortunately, these rhymes are still a part of education which does not allow children to deduce meanings which are contemporary to the Pakistani society. In addition, the tradition of singing these rhymes is so firm that teachers and parents appear to overlook the message conveyed through these rhymes. Similarly, educationalists and curriculum developers in the education ministry of Pakistan seem to be equally ignorant as they neither replace nor amend the themes in order to project the current or desire social roles from the Pakistani society. Else, I should say that promoters of these rhymes are themselves ignorant of the symbols and their significance in the development of children. This might be the reason that Pakistani society is still aspiring for the freedom of thoughts and speech.

\section{Conclusion}

The paper concludes that nursery rhymes are an influential medium of creating and transmitting social behaviors in a society. Through rhymes, children conceptualize the expectations of society and the expected roles in a society. Their understanding reflects from their social behaviors. As these rhymes have been learnt and taught across generations, it may be assumed that a considerable part of the society still follows same gender roles on the basis of their childhood learning. In such a case, it is important to acknowledge the power of rhymes and its symbolic interaction with the society for propagating beneficial messages. Also, it is the informal usage and an underestimation of the power of rhymes that does not motivate the ambassadors of education to use rhymes as a mean of change in the society. On this note, nursery rhymes must be seen as a powerful tool for the modification of social attitudes and behaviors among children; and so its importance must not be overlooked. In the context of Pakistan, the paper suggests that the knowledge communicated through nursery rhymes is stereotypical. It neither projects the contemporary social roles of men and women, nor is it transforming the perception of gender roles in the society. In either case, attention is required from the state of Pakistan, who regulates the ministry of education, to revise educational curriculum thoroughly. In general, there is hardly any revision observed in educational curriculum for any age, including nursery curriculum. It tends to require a collaborative efforts by educationalist, linguistics and anthropologists where status of women and perceptions about certain gender roles such as mother, father, wife and sisters must be relooked in order to broaden the minds of children. It is a necessary measure for improving the conditions of Pakistan. It may become a problem if the message of gender biases- that is somewhat incorrect- keep flowing from generations to generations as it will freeze the misconception about gender in the society. Thus, the power of language must be exercised in providing new and vibrant meanings of age-old concepts for revolutionizing social behaviors of people.

\section{References}

(2007). A Ten Year Review. Human Development in South Asia. NewYork: Oxford University Press. Butler, J., 1990. Gender Trouble: Feminism And The Subversion Of I dentity. London: Routledge. Connell, R.W. (2002). The question of gender. Gender. UK: Blackwell Synergy. 
Doležalová, H. (2007). A comparison of Czech and English nursery rhymes. Retrieved 27- 12-2012 from is.muni.cz/th/84379/pedf_m/DP.doc

Faridi, T. (2009). The Changing Role of Women in Pakistan. Ann Arbor: University of Michingan.

Heath, S.B. (1982). What no bedtime story means: narrative skills at home and school. Language in society, vol 11(1), pp. 49-76.

Heath, S.B. (1982). What no bedtime story means: narrative skills at home and school. Language in Society, vol 11 (1), pp. 49-76.

Jahangir, A. (1988). How far are penal laws effective in protecting women. Pakistan, pp. 33-38.

Jehan, Q. (2000). Role of Women in Economic Development of Pakistan. Pakistan Research Repository. University of Balochistan.

Korbin, J.E. (1981). Child Abuse and Neglect: Cross Cultural Perspectives. Ewing: University of California Press.

Lentricchia, F. and McLaughlin, T. (1995). Critical Terms for Literary Studies. 2nd ed. Chicago: Univeristy of Chicago Press. p. 80-90

Moore, H. (1994). The cultural constitution of gender. The Polity Reader in Gender Studies. Cambridge: Polity Press, p.14-21.

Mumtaz, Z. (not dated). Agar Nagar Ki Nanhi Nazmain. Lahore: Oxford University Press. Mushtaq, K. and Rasul,S. (2012). Identity construction in nursery rhymes: A gender Based study. Language in India, Vol 12.

Ochs, E. \& Capps, L. (1996). Narrating the Self. Annual Review of Anthropology, 25, pp.19 -43.

Ochs, E. \& Schieffelin,B. (1979). Developmental Pragmatics. New York: Academic Press Ochs, E. (1988). Culture and Language Development: Language Acquisition and Language Socialization in a Samoan Village. New York: Cambridge University Press.

Piaget, J. (1952). Language and Thought of the Child. London: Routledge and Kegan Paul. Schieffelin,B. \& Ochs, E. (1986). Language socialization. Annual Review of Anthropology, vol 1, pp.163-191

Vygotsky, L. S. (1962). Thought and Language. Cambridge: MIT Press.

Wallowitz, L. (2004). Reading as Resistance: Gendered Messages in Literature and Media. The English J ournal, 93 (3), pp.26-31

\section{APPENDIX}

\section{Appendix 1: Piyari baji}

Subuh sawairay roz jagain

Payala bhar kar dudh pilain

Makhan toast khilati hai

Aur tamiz sikhati hai

Roz kahani ham ko sunain

Rat ko apnay sath sulaen
Awakes us daily early morning

Makes us drink a bowl full of milk

Makes us eat bread and butter

and teaches us manners

narrates a story to us daily

Put us to sleep with her at night

(Mushtaq and Rasul, 2012:15)

\section{Appendix 2: Machali Ka Bacha}

Machli ka

bacha anday

say nikla

paani main

phisla abbu

nay pakra

bhayya nay

kataa mama

nay pakaya 
sab nay mil

kar khaya

bara maza

ayaaaa!!

\section{Appendix 3: Jab Hum Chottey the}

Alif $\mathrm{Ba} T \mathrm{Te}$

Hum Chote they

ammi marti thi

hum rotay thay

abu mithai late the

ham khate the ami

jalti thi

hum hanstay thay

\section{Appendix 4: Cham Cham}

billi ne diye do

bachey allah

mian sachey

sachey sachey

jaingey bhai ki

dulhan laaingey

bhai ki dulhan

kali sau

nakhron wali ek

nakhra tuut

gaya bhai ka

mun sooj gaya!

\section{Appendix 5: Tot Batot ki shadi}

tot batot nay kar lee shadi

Ab na who shokhi ab na who shaikhi

Ab na who uski dheenga mushti

Khatam hui sab ha ha he he

Khatam hui sari azadi

Tot batot nay kar lee shadi

Ab na who ronaq hay na maila

Din bhar ghar main rahay akaila

Biwi lay gaye paisa dhaila

Mery Allah yeh barbadi

Tot batot nay karli Shadi

Appendix 6: Tot Batot Ki Appa

tot batot ki appa

Zahir mein aka baka hai

Laikin who badi ladaka hai
Tot Batot is finally Married

Now all his humor and boasting ended No more you see his fisticuffs No more you hear his ha ha he he Now the freedom period has ended Tot Batot in finally married Neither that bloom nor that fun is here All day Long, he remains alone

The wife has flown with all the money. My God! What a tragedy

Tot Batot is finally married

(Mushtaq and Rasul, 2012:7)
Tot Batot's elder sister

In looks quite fragile

In fact, rather quarrelsome 
Kuch kaho to forum ladti hai

Ladti hay aur ro parti hai

Yeh kah kar shor machati hai

Sun lo main baby apa hoon

Mein Tot batot ki apa hoon
A little provoked, she begins to fight She fights and she weeps Saying this she makes a noise Listen! I am baby apa

I am Tot Batot's apa

(Mushtaq and Rasul, 2012:6) 